Nutr Metab Cardiovasc Dis. 2010 July ; 20(6): 419-425. doi:10.1016/j.numecd.2010.02.017.

\title{
Stroke in women
}

\author{
Sylvia Wassertheil-Smoller \\ Albert Einstein College of Medicine, 1300 Morris Park Avenue, Bronx, NY 10461, United States
}

\begin{abstract}
Aims-The aim of this article is to provide an overview of stroke in women and describe modifiable and non-modifiable risk factors for stroke.

Data synthesis-Data supporting this article come from the National Center for Health Statistics, from American Heart Association publications, and from some of the large, multicenter trials and observational studies that inform guidelines for prevention of stroke. These data indicate that stroke is the third leading cause of death in women, that risk for stroke rises rapidly with age, and that the strongest risk factors for stroke are high blood pressure and atrial fibrillation, as well as diabetes and smoking. Risk rises rapidly when two or more risk factors are present. Hormone therapy in postmenopausal women increases risk of ischemic, but not hemorrhagic stroke, by 40$50 \%$. Biomarkers of inflammation are associated with stroke risk. Other risk factors include certain lipids, physical inactivity, and low potassium diets. Although there has been improvement in the past decade, control of hypertension is inadequate in older women and many strokes could be prevented by better treatment of hypertension.
\end{abstract}

Conclusion-Death and disability from stroke can be reduced with modification, treatment, and better control of risk factors like hypertension, diabetes and atrial fibrillation.

\section{Keywords}

Stroke in women; Ischemic stroke; Hemorrhagic stroke; Hormone therapy; Risk factors for stroke

Stroke is a devastating event which often leads to death or major disability. It is the third leading cause of death after heart disease and cancer. Death rates from stroke have dropped dramatically since the 1950s (Figure 1), largely due to improving, but still inadequate, control of high blood pressure and other risk factors. The male to female ratio of death rates has remained fairly constant at 1.1 going down somewhat by 2005. In 2005 the age-adjusted death rates for stroke in women were 45.6 per 100,000 [1]. Black women have higher rates than white women. Stroke death rates rise rapidly with increasing age.

\section{What is a stroke?}

Stroke is defined as the rapid onset of a persistent neurologic deficit attributed to an obstruction or rupture of the arterial system that is not due to brain trauma, tumor, or other cause. There are two major kinds of stroke: hemorrhagic and ischemic. Hemorrhagic stroke 
is caused by rupture of a blood vessel resulting in bleeding in the brain. Intracerebral hemorrhage (ICH) refers to bleeding directly into the brain. Subarachnoid hemorrhage ( $\mathrm{SAH}$ ) is bleeding outside the brain but inside the cranial space and is usually due to an aneurysm. Ischemic stroke occurs when the supply of blood to parts of the brain is diminished or blocked, usually due to obstruction due to a clot, an embolism arising in the heart or elsewhere in the body, or a generally low perfusion of blood through the brain. Ischemic strokes may be classified with regard to the area of the brain involved and the extent of the stroke (Oxfor-shire classification) and/or with regard to underlying stroke mechanism (TOAST criteria), which requires detailed imaging work-up. Transient Ischemic Attacks (TIAs), sometimes called "mini-strokes," are caused by brief interruptions of flow of blood to the brain, with symptoms resolved within $24 \mathrm{~h}$. They are a strong risk factor for subsequent stroke.

\section{Prevalence and incidence of stroke}

Data from the Centers for Disease Control (CDC) indicate that in $20052.7 \%$ of men and $2.5 \%$ of women had a history of stroke, with rates for non-Hispanic blacks (4.0\%) being nearly twice as high as for non-Hispanic whites (2.3\%). Prevalence rates rise steeply with age. Women have similar rates to men at ages $60-79$ (7.6\% and $7.8 \%$ respectively), and lower prevalence than men at ages 80 and over (13.5\% and $17.1 \%$ respectively) [2]. In the Women's Health Initiative (WHI), a set of studies of heart disease, stroke, cancer and other health problems of postmenopausal women in 160,808 women ages 50-79 at enrollment in 1994-1998, 1.3\% reported at enrollment that they had been told by a doctor they had had a stroke. These were community-dwelling, generally healthy women [3].

Incidence of stroke is higher among black women than among white women, as is ageadjusted stroke mortality rate $(60.7 / 100,000$ and $44 / 100,000$ respectively). Hispanic women have lower stroke mortality rates $(33.5 / 100,000)$ [1]. In the Atherosclerosis Risk in Communities (ARIC) cohort of 15,792 persons ages 45-64 followed for an average of 7.2 years, the age-adjusted incidence of first-ever total stroke among white women was 1.49 per 1000 person-years and it was more than double for black women (3.96 per 1000 personyears) [4]. It is estimated that among women ages 40 or greater, the mortality is $24 \%$ in one year after the first stroke [2].

Hemorrhagic stroke accounts for 15-20\% of all strokes. In the WHI, among 3304 strokes, $18.7 \%$ were hemorrhagic. Case-fatality rates for hemorrhagic stroke are higher than for ischemic stroke and may be as high as 50\% or more [5-7]. In the ARIC Study, the 30-day age and race adjusted case-fatality rate in women was 4.7 times higher for hemorrhagic as for ischemic stroke (30.4\% versus 6.5\%) [4].

Symptoms of stroke are:

- Sudden numbness or weakness of the face, arm or leg (especially on one side of the body)

- Sudden confusion, trouble speaking or understanding speech

- Sudden trouble seeing in one or both eyes 
- Sudden trouble walking, dizziness, loss of balance or coordination

- Sudden severe headache with no known cause

However, there is insufficient awareness of these 5 warning symptoms In a 2005 Behavioral Risk Factor Surveillance System (BRFSS) survey of respondents in 14 states, $41.5 \%$ of women were aware of these 5 symptoms and said they would call 911 if they thought someone was having a stroke. The awareness was lower among Hispanics and blacks $[2,8]$. Awareness is important because in ischemic stroke, early treatment may make a profound difference in outcome.

Disability is substantial in women following a stroke. The Glasgow Outcome Scale assesses post stroke function, using the following five categories: good recovery, moderate disability, severe disability, persistent vegetative state, and death. In the Hormones and Biomarkers Predicting Stroke (HaBPS) Study, a nested case-control study of ischemic stroke in the Women's Health Initiative Observational Study, among 972 ischemic strokes, only $23 \%$ had good recovery, $35 \%$ were moderately disabled and $32 \%$ were severely disabled; $0.4 \%$ had vegetative survival (unpublished data).

\section{Risk factors for stroke}

There are a number of non-modifiable risk factors for stroke, such as age, race, and genetic factors. However, most of the strongest risk factors are modifiable or controllable, such as hypertension, diabetes, atrial fibrillation, use of hormone therapy and others. In many, but not all of these cases, clinical trials have demonstrated the efficacy of risk factor modification and treatment.

\section{Hypertension}

Hypertension, generally defined as systolic blood pressure $>=140 \mathrm{mmHg}$ and/or diastolic blood pressure $>=90 \mathrm{mmHg}$, or being on antihypertensive medication, is a strong riskfactor for both hemorrhagic and ischemic stroke. Under this definition, in 2005-2006, 29\% of all U.S. adults 18 years and older were hypertensive, $68 \%$ were treated with antihypertensive drugs and of those treated, 64\% had their blood pressure controlled [9]. While overall, the rate of control of hypertension in adults 18-74 has improved from $10 \%$ of hypertensives in 1976-1980 to $34 \%$ in 2000 [10], to $44 \%$ in 2005-2006 [9], largely through the efforts of the National High Blood Pressure Education Council, it is still far short of desirable particularly among postmenopausal women. In the WHI Observational Study the prevalence of hypertension ranged from $27 \%$ in those 50-59 and double that (53.4\%) in women 70-79. About two-thirds were being pharmacologically treated. Of the younger age group of hypertensives (those aged 50-59) about $40 \%$ had their blood pressure under control (i.e. SBP/DBP < 140/90) while in those 70-79 only $29 \%$ had it controlled [11]. It is shocking that among the older women, who are most at risk of stroke, $70 \%$ of hypertensives were uncontrolled! International data from the I-SEARCH study (International Survey Evaluating Microalbinuria Routinely by Cardiologists) conducted in 26 countries, including 18,017 patients, indicated that women had higher systolic blood pressure than men by $2 \mathrm{mmHg}$ with 
no difference in diastolic blood pressure. Overall, blood pressure control was lower in women than in men (30.6\% versus $33.6 \%$ respectively) [12].

Clinical trials have shown that treatment of hypertension reduces risk [13]. Isolated systolic hypertension (defined as $\mathrm{SBP}>=140 \mathrm{~mm} \mathrm{Hg}$ and $\mathrm{DBP}<90 \mathrm{mmHg}$ ) is common in the elderly and is a strong risk factor for stroke. In the WHI Observational study of 93,676 women, $17 \%$ of women had isolated systolic hypertension [13]. Treating isolated systolic hypertension in persons 60 years of age or older reduced the risk of stroke by $36 \%$. Both ischemic and hemorrhagic stroke showed reduced risk [14,15]. Effect of treatment was observed within the first year for hemorrhagic stroke and the second year for ischemic stroke. The HYVET study (Hypertension in the Very Elderly Trial) of 3845 patients 80 years of age or older from Europe, China, Australasia and Tunisia, showed that treating elderly patients with indapamide with or without perindopril to a goal of $150 / 80 \mathrm{mmHg}$ reduced risks of stroke, heart failure and death [16].

The Blood Pressure Lowering Treatment Trialists' Collaboration did a meta-analysis of 31 trials including 190,606 patients and concluded that lowering blood pressure in both younger and older adults protects against cardiovascular events with no evidence of variation by different drug classes. It's the lowered blood pressure that is important [17].

Diuretics are generally the first-line treatment for hypertension. However, Angiotensin converting enzyme inhibitors (ACE-inhibitors), angiotensin receptor blockers (ARBs) and calcium channel blockers are also recommended in certain subgroups [10]. ACE-inhibitors and ARBs are contraindicated in women who are or plan to be pregnant. In WHI among the 30,219 hypertensive women with no prior history of cardiovascular disease 57\% were receiving monotherapy with a diuretic, ACE-inhibitor, beta-blocker or calcium channel blocker [18]. Most women however, may require more than one drug to control their blood pressure [10].

\section{Diabetes}

Diabetes confers a 2-6-fold increase in risk of stroke independently of other risk factors. The impact of diabetes is greater in women than in men $[19,20]$. The prevalence of diabetes in women ages 20 years and older is $10.2 \%$ and is double that in women 60 years and older [21]. Because high blood pressure in diabetic women increases risk of stroke and other cardiovascular events; the recommended goal blood pressure for diabetics is SBP $<130$, DBP $<85[10]$.

The Diabetes Prevention Program (DPP), a 27-center clinical trial in 3234 participants of lifestyle changes and treatment with the oral antidiabetic agent metformin, showed that modest weight loss and increased physical activity or treatment with metformin was effective in preventing or delaying the onset of type 2 diabetes in men and women who were overweight [22]. The intensive lifestyle modification group reduced their risk of developing diabetes by $58 \%$. Persons older than 60 years reduced their risk by $70 \%$. Lifestyle changes were more effective than metformin. The incidence of diabetes in the 2191 women was 10.3 in the placebo group, 7.6 in the metformin group and 5.0 in the lifestyle group over an average of 2.8 years of follow-up. 


\section{Hormone therapy}

The WHI randomized clinical trials of estrogen plus progestin $(0.625 \mathrm{mg} / \mathrm{d}$ of conjugated equine estrogen plus $2.5 \mathrm{mg} / \mathrm{d}$ of medroxyprogesterone acetate) and estrogen alone versus placebo demonstrated unequivocally that estrogen therapy with or without progestin, increases the risk of stroke by 40-50\% [23,24]. The hazard ratio for estrogen plus progestin versus placebo for ischemic stroke was 1.44 (95\% CI, 1.09-1.90) and for hemorrhagic stroke it was 0.82 (95\% CI, 0.43-1.56) (Figure 2). For all strokes with adjustment for adherence, the HR was 1.50 (95\% CI, 1.08-2.08) [24]. For estrogen alone $(0.625 \mathrm{mg} / \mathrm{d}$ of conjugated equine estrogen) in hysterectomied women the hazard ratio was 1.55 (1.19$2.01)$ for ischemic stroke and $0.64(0.35,1.18)$ for hemorrhagic stroke [23]. The effect was apparent in all subgroups. In addition, hormone therapy increased the risk of dementia and mild cognitive impairment $[25,26]$. As a result of these trials the FDA labeling states that hormone therapy should be given in the lowest dose and for the shortest time to relieve menopausal symptoms. However, it is not known how short or long that time may be. In WHI the increased risk of stroke became apparent by one year of therapy.

\section{Smoking}

Smoking is associated with a 2-fold increase in risk of ischemic stroke and an even higher increased risk of hemorrhagic stroke [20]. Smoking together with oral contraceptive use confers a much higher risk than either of these factors alone. Compared to non-smoking, non-OC users, women who both smoked and used OC had a 7.2 higher risk of ischemic stroke (95\% CI: 3.2-16.1), while the increase in risk for smokers and non-OC users was 1.3 and for non-smokers who used OC it was 2.1. The pattern was the same for hemorrhagic stroke, though perhaps not as pronounced [27].

\section{Atrial fibrillation}

The prevalence of atrial fibrillation increases with age from less than $1 \%$ in those 50-59 to $9 \%$ in those $80-89$ [19,20]. Atrial fibrillation increases the risk of stroke three to fourfold. The effect of afib in women is greater than in men [28]. Aspirin therapy reduces stroke risk by about $20 \%$ and warfarin therapy reduces it by about $60 \%$ [20]. Anti-coagulation poses the risk of excessive bleeding particularly when there is not sufficient monitoring of dose. However, it is recommended for all those with non-valvular atrial fibrillation whose stroke risk is 4\% a year or greater. A commonly used risk stratification scheme is the CHADS [29]. This scheme assigns points to four conditions: congestive heart failure, hypertension, age > 75, diabetes, prior stroke or TIA. Each of the first three get one point and history of stroke or TIA gets 2 points. Those with 3 or more points are at high risk. However, women with a history of stroke or TIA and none of the other risk factors should be given warfarin unless contraindicated. There are several other risk stratification schemes which may be used to guide decisions about anticoagulation, such as the Atrial Fibrillation Investigators (AFI) [30] and Stroke Prevention in Atrial Fibrillation (SPAF) [31] risk stratification schemes as well as a risk score from the Framingham study [32]. These were compared and tested against outcomes in a cohort of 13,559 adults with atrial fibrillation; follow-up was for a median of 6.0 years [33]. The authors concluded that these risk schemes have comparable ability to 
predict ischemic stroke but that all are poor predictors. Stroke rates vary 20 -fold among atrial fibrillation patients and a better risk stratification scheme is needed.

\section{Depression}

Depression is an insufficiently recognized risk factor for stroke and mortality in women. The prevalence of depressive symptoms in older women was found to be 11-15\% in the WHI and is higher in African-Americans and Hispanics than in whites and is lowest in Asians [34]. Whether it is causal or a marker or an early manifestation of subclinical disease is not known. In the WHI among women who had a history of cardiovascular disease, the hazard ratio associated with depressive symptoms as measured on a screening instrument (shortened version of the CES-D) and controlling for multiple covariates was 1.40 (95\% CI: 1.08-1.81) [34]. In the SHEP trial, while baseline depressive symptoms were not related to subsequent events, an increase in depression in women of units on the CES-D scale was associated with a hazard ratio for stroke of 1.29 (95\% CI: 1.07-1.34) [35]. Although there is no evidence that treating depression will reduce stroke risk, it is important for clinicians to recognize this condition and to pay special attention to controlling other modifiable risk factors in women who are mildly or moderately depressed and particularly in those who have a history of cardiovascular disease.

\section{Lipids}

The role of lipids in risk of stroke in women is not firmly established [20]. WHI data suggest that low HDL levels and high triglycerides may be risk factors (unpublished data). A metaanalysis of statin trials by Amarenco and colleagues [36] indicated that statin treatment reduced stroke risk by $21 \%$ (OR $=0.79,95 \% \mathrm{CI}: 0.73-0.85)$, providing considerable evidence that reductions in LDL-cholesterol are important in prevention of stroke. The metaanalysis indicated that for each $10 \%$ reduction in LDL-C risk of all strokes was reduced by 15\% (95\% CI: 6.7-23.6\%). Hemorrhagic strokes were not increased with statin therapy. In many observational studies however, levels of LDL-C do not predict stroke.

\section{Obesity}

The relationship of obesity to stroke risk is somewhat controversial. While it is established that obesity increases the risk of hypertension, diabetes and dyslipidemia, it is not clear if excess weight influences stroke risk independently of these factors. Overweight is usually defined as a body mass index (BMI) of 25-29.9. BMI is calculated as weight in kilograms divided by height in meters squared. A BMI of 30 or above is considered obese The prevalence of overweight and obesity is high in the United States, with data from the National Health and Nutrition Examinations Survey showing that $66 \%$ of the adult population fall into these two categories and $30 \%$ fall into the obese category $[37,38]$. Several studies have found that higher BMI was associated with increased stroke risk The Nurses' Health Study of 116,759 women aged 30-55 at enrollment reported that during 16 years of follow-up, women with BMI $>=27$ had higher ischemic stroke risk compared with $\mathrm{BM}<21$, which increased with increasing levels of BMI [39]. There was an inverse relationship which did not reach statistical significance, between hemorrhagic stroke and BMI. However, other studies have shown U or J shaped relationships between BMI and 
stroke, with increased risk of mortality at low BMIs. The Systolic Hypertension in the Elderly Program (SHEP), a randomized, placebo-controlled clinical trial, found that in women with isolated systolic hypertension who were 60 years or older there was no relationship of BMI to stroke and that in the treated group there was a $\mathrm{U}$ or $\mathrm{J}$ shaped relationship between BMI and stroke. The BMI nadir was a BMI of 29 , with risk increasing steeply at BMIs below 24 [40]. A systematic review of 40 studies with 250,152 patients by Romero-Corral and colleagues found an increased risk in total mortality, after adjustment for multiple potential confounders, among those with BMI less than 20 and lowest risk of total mortality was for those with BMI 25-29.9 [41], similar to the findings in SHEP. The authors suggest that the results could be explained by the inability to discriminate between body fat and lean body mass. It may be that waist/hip circumference is a better index of adiposity than BMI and it may have a stronger relationship to stroke. There are no trials showing that weight loss reduces stroke risk independently of its effect on risk factors such as hypertension.

\section{Biomarkers}

Inflammatory biomarkers have been associated with risk of stroke. C-reactive protein (CRP) is associated with a twofold increase in risk [42,43]. Lipoprotein-associated phospholipase $\mathrm{A}_{2}$ (Lp-PLA $\mathrm{A}_{2}$ ) is an enzyme largely bound to low-density lipoprotein. Several studies have found elevations of $\mathrm{Lp}-\mathrm{PLA}_{2}$ are associated with excess stroke risk independently of lipids and other risk factors. In the ARIC (Atherosclerosis Risk in Communities) study, high levels of Lp-PLA 2 were associated with higher risk of ischemic stroke. Highest risk was found in individuals with both high CRP and high Lp-PLA 2 levels [44]. In the Hormones and Biomarkers Predicting Stroke (HaBPS) study, a case-control study nested in the WHI Observational Study, Lp-PLA 2 was associated with a 56\% increase in risk of ischemic stroke in women who did not use hormone therapy, OR $=1.56$ (95\% CI: 1.10-2.22) after controlling for multiple covariates. There was no relationship among women who were using hormones [45]. Here also, risk was highest in those with both high CRP and high Lp$\mathrm{PLA}_{2}$. There have been no studies indicating that lowering these factors will reduce stroke risk.

\section{Genetics and other risk factors}

The growing area of genome-wide association studies has found several variants associated with stroke, including a genetic locus on chromosome 12p13 [46]. Several other genomewide association studies are in progress.

Other risk factors have also been identified, including sleep-disordered breathing, physical inactivity, migraine in younger women, high homocysteine levels, infection with cytomegalovirus, alcohol or drug abuse [20]. Dietary factors are also associated with risk of ischemic stroke. Fish oils and low-sodium, high potassium diets may be protective. Unfortunately no clinical trials have demonstrated that reducing these potential risk factors reduces stroke risk. Risk rapidly escalates when women have a combination of risk factors. Figure 3 shows 10-year stroke risk predicted by the Framingham Stroke Risk equations for women [47]. 


\section{Conclusions}

Stroke risk is multifactorial but the strongest risk factors are hypertension and atrial fibrillation. Control of hypertension, though improving, is inadequate in older women. Stroke risk can be reduced in women with atrial fibrillation by treatment with warfarin, and when anticoagulation is contraindicated, aspirin. Other risk factors include diabetes, smoking, markers of inflammation, dietary factors and genetic predisposition. Increasing depressive symptoms may be a marker for impending stroke. There is insufficient awareness of warning symptoms of stroke and public health efforts should be mounted to increase awareness so that stroke victims can get more immediate care which would limit the damage.

\section{References}

1. Statistics NCfH. Health, United States. Hyattsville, MD: National Center for Health Statistics; 2007. Available at: http://www.cdc.gov/nchs/hus.htm

2. Lloyd-Jones D, Adams R, Carnethon M, De Simone G, Ferguson TB, Flegal K, et al. Heart disease and stroke statistics - 2009 update: a report from the American Heart Association Statistics Committee and Stroke Statistics Subcommittee. Circulation. 2009; 119(3):480-6. [PubMed: 19171871]

3. Hays J, Hunt JR, Hubbell FA, Anderson GL, Limacher M, Allen C, et al. The Women's Health Initiative recruitment methods and results. Ann Epidemiol. 2003; 13(9 Suppl):S18-77. [PubMed: 14575939]

4. Rosamond WD, Folsom AR, Chambless LE, Wang CH, McGovern PG, Howard G, et al. Stroke incidence and survival among middle-aged adults: 9-year follow-up of the Atherosclerosis Risk in Communities (ARIC) cohort. Stroke. 1999; 30(4):736-43. [PubMed: 10187871]

5. Hanel RA, Xavier AR, Mohammad Y, Kirmani JF, Yahia AM, Qureshi AI. Outcome following intracerebral hemorrhage and subarachnoid hemorrhage. Neurol Res. 2002; 24(Suppl. 1):S58-62. [PubMed: 12074438]

6. Ayala C, Croft JB, Greenlund KJ, Keenan NL, Donehoo RS, Malarcher AM, et al. Sex differences in US mortality rates for stroke and stroke subtypes by race/ethnicity and age, 1995-1998. Stroke. 2002; 33(5):1197-201. [PubMed: 11988590]

7. Woo D, Sauerbeck LR, Kissela BM, Khoury JC, Szaflarski JP, Gebel J, et al. Genetic and environmental risk factors for intracerebral hemorrhage: preliminary results of a population-based study. Stroke. 2002; 33(5):1190-5. [PubMed: 11988589]

8. Greenlund KJ, Neff LJ, Zheng ZJ, Keenan NL, Giles WH, Ayala CA, et al. Low public recognition of major stroke symptoms. Am J Prev Med. 2003; 25(4):315-9. [PubMed: 14580633]

9. Ostchega Y, Yoon SS, Hughes J, Louis T. Hypertension awareness, treatment, and control continued disparities in adults: United States, 2005-2006. NCHS Data Brief. 2008; 3:1-8. [PubMed: 19389317]

10. Chobanian AV, Bakris GL, Black HR, Cushman WC, Green LA, Izzo JL Jr, et al. The Seventh Report of the Joint National Committee on prevention, detection, evaluation, and treatment of high blood pressure: the JNC 7 report. JAMA. 2003; 289(19):2560-72. [PubMed: 12748199]

11. Wassertheil-Smoller S, Anderson G, Psaty BM, Black HR, Manson J, Wong N, Francis J, et al. Hypertension and its treatment in postmenopausal women. Baseline data from the women's health initiative Hypertension. 2000; 36:780-9.

12. Thoenes M, Neuberger HR, Volpe M, Khan BV, Kirch W, Böhm M. Antihypertensive drug therapy and blood pressure control in men and women: an international perspective. J Hum Hypertens. 2009 Oct 1. Epub ahead of print.

13. Langford HG, Stamler J, Wassertheil-Smoller S, Prineas RJ. All-cause mortality in the hypertension detection and follow-up program: findings for the whole cohort and for persons with 
less severe hypertension, With and without other traits related to risk of mortality. Prog Cardiovasc Dis. 1986; XXIX:29-54. [PubMed: 3538178]

14. Shep CRG. Prevention of stroke by antihypertensive drug treatment in older persons with isolated systolic hypertension. Final results of the systolic hypertension in the elderly program (SHEP). JAMA. 1991; 265:3255-64. [PubMed: 2046107]

15. Perry HM Jr, Davis BR, Price TR, Applegate WB, Fields WS, Guralnik JM, et al. Effect of treating isolated systolic hypertension on the risk of developing various types and subtypes of stroke: the systolic hypertension in the elderly program (SHEP). JAMA. 2000; 284(4):465-71. [PubMed: 10904510]

16. Beckett NS, Peters R, Fletcher AE, Staessen JA, Liu L, Dumitrascu D, et al. HYVET study group, treatment of hypertension in patients 80 years of age or older. N Engl J Med. 2008 May 1; 358(18):1887-98. Epub 2008 Mar 31. [PubMed: 18378519]

17. Turnbull F, Neal B, Ninomiya T, Algert C, Arima H, Barzi F, et al. Blood Pressure Lowering Treatment Trialists' Collaboration. Effects of different regimens to lower blood pressure on major cardiovascular events in older and younger adults: meta-analysis of randomised trials. BMJ. 2008 May 17; 336(7653):1121-3. Epub 2008 May 14. [PubMed: 18480116]

18. Wassertheil-Smoller S, Psaty B, Greenland P, Oberman A, Kotchen T, Mouton C, et al. Association between cardiovascular outcomes and antihypertensive drug treatment in older women. JAMA. 2004; 292(23):2849-59. [PubMed: 15598916]

19. Goldstein LB, Adams R, Alberts MJ, Appel LJ, Brass LM, Bushnell CD, et al. Primary prevention of ischemic stroke: a guideline from the American Heart Association/American Stroke Association Stroke Council: cosponsored by the Atherosclerotic Peripheral Vascular Disease Interdisciplinary Working Group; Cardiovascular Nursing Council; Clinical Cardiology Council; Nutrition, Physical Activity, and Metabolism Council; and the Quality of Care and Outcomes Research Interdisciplinary Working Group. Circulation. 2006; 113(24):e873-923. [PubMed: 16785347]

20. Goldstein LB, Adams R, Alberts MJ, Appel LJ, Brass LM, Bushnell CD, et al. Primary prevention of ischemic stroke: a guideline from the American Heart Association/American Stroke Association Stroke Council: cosponsored by the Atherosclerotic Peripheral Vascular Disease Interdisciplinary Working Group; Cardiovascular Nursing Council; Clinical Cardiology Council; Nutrition, Physical Activity, and Metabolism Council; and the Quality of Care and Outcomes Research Interdisciplinary Working Group: the American Academy of Neurology affirms the value of this guideline. Stroke. 2006; 37(6):1583-633. [PubMed: 16675728]

21. Clearinghouse NDI. NIH Publication No. 08-3892. 2008

22. Knowler WC, Barrett-Connor E, Fowler SE, Hamman RF, Lachin JM, Walker EA, et al. Reduction in the incidence of type 2 diabetes with lifestyle intervention or metformin. $\mathrm{N}$ Engl $\mathrm{J}$ Med. 2002; 346(6):393-403. [PubMed: 11832527]

23. Hendrix SL, Wassertheil-Smoller S, Johnson KC, Howard BV, Kooperberg C, Rossouw JE, et al. Effects of conjugated equine estrogen on stroke in the Women's Health Initiative. Circulation. 2006; 113(20):2425-34. [PubMed: 16702472]

24. Wassertheil-Smoller S, Hendrix S, Limacher M, Heiss G, Kooperberg C, Baird A, et al. Effect of estrogen plus progestin on stroke in postmenopausal women: the women's health initiative: a randomized trial. JAMA. 2003; 289(20):2673-84. [PubMed: 12771114]

25. Shumaker SA, Legault C, Kuller L, Rapp SR, Thal L, Lane DS, et al. Conjugated equine estrogens and incidence of probable dementia and mild cognitive impairment in postmenopausal women: Women's Health Initiative Memory Study. JAMA. 2004; 291(24):2947-58. [PubMed: 15213206]

26. Shumaker SA, Legault C, Rapp SR, Thal L, Wallace RB, Ockene JK, et al. Estrogen plus progestin and the incidence of dementia and mild cognitive impairment in postmenopausal women: the Women's Health Initiative Memory Study: a randomized controlled trial. JAMA. 2003; 289(20): 2651-62. [PubMed: 12771112]

27. Ischaemic stroke and combined oral contraceptives: results of an international, multicentre casecontrol study. WHO Collaborative Study of Cardiovascular Disease and Steroid Hormone Contraception. Lancet. 1996; 348(9026):498-505. [PubMed: 8757151]

28. Fang MC, Singer DE, Chang Y, Hylek EM, Henault LE, Jensvold NG, et al. Gender differences in the risk of ischemic stroke and peripheral embolism in atrial fibrillation: the AnTicoagulation and 
Risk factors In Atrial fibrillation (ATRIA) study. Circulation. 2005; 112(12):1687-91. [PubMed: 16157766]

29. Gage BF, Waterman AD, Shannon W, Boechler M, Rich MW, Radford MJ. Validation of clinical classification schemes for predicting stroke: results from the National Registry of Atrial Fibrillation. JAMA. 2001; 285(22):2864-70. [PubMed: 11401607]

30. Risk factors for stroke and efficacy of antithrombotic therapy in atrial fibrillation. Analysis of pooled data from five randomized controlled trials. Arch Intern Med. 1994; 154(13):1449-57. [PubMed: 8018000]

31. Hart RG, Pearce LA, McBride R, Rothbart RM, Asinger RW. Factors associated with ischemic stroke during aspirin therapy in atrial fibrillation: analysis of 2012 participants in the SPAF I-III clinical trials. The Stroke Prevention in Atrial Fibrillation (SPAF) Investigators. Stroke. 1999; 30(6):1223-9. [PubMed: 10356104]

32. Wang TJ, Massaro JM, Levy D, Vasan RS, Wolf PA, D'Agostino RB, et al. A risk score for predicting stroke or death in individuals with new-onset atrial fibrillation in the community: the Framingham Heart Study. JAMA. 2003; 290(8):1049-56. [PubMed: 12941677]

33. Fang MC, Go AS, Chang Y, Borowsky L, Pomernacki NK, Singer DE. Comparison of risk stratification schemes to predict thromboembolism in people with nonvalvular atrial fibrillation. $\mathrm{J}$ Am Coll Cardiol. 2008; 51(8):810-5. [PubMed: 18294564]

34. Wassertheil-Smoller S, Shumaker S, Ockene J, Talavera GA, Greenland P, Cochrane B, et al. Depression and cardiovascular sequelae in postmenopausal women. The Women's Health Initiative (WHI) Arch Intern Med. 2004; 164(3):289-98.

35. Wassertheil-Smoller S, Applegate WB, Berge K, Chang CJ, Davis BR, Grimm R Jr, et al. Change in depression as a precursor of cardiovascular events. SHEP Cooperative Research Group (Systoloc Hypertension in the elderly). Arch Intern Med. 1996; 156(5):553-61. [PubMed: 8604962]

36. Amarenco P, Labreuche J, Lavallee P, Touboul PJ. Statins in stroke prevention and carotid atherosclerosis: systematic review and up-to-date meta-analysis. Stroke. 2004; 35(12):2902-9. [PubMed: 15514180]

37. Hedley AA, Ogden CL, Johnson CL, Carroll MD, Curtin LR, Flegal KM. Prevalence of overweight and obesity among US children, adolescents, and adults, 1999-2002. JAMA. 2004; 291(23):2847-50. [PubMed: 15199035]

38. Ogden CL, Carroll MD, McDowell MA, Flegal KM. Obesity among adults in the United States no statistically significant chance since 2003-2004. NCHS Data Brief. 2007; 1:1-8. [PubMed: 19389313]

39. Rexrode KM, Hennekens CH, Willett WC, Colditz GA, Stampfer MJ, Rich-Edwards JW, et al. A prospective study of body mass index, weight change, and risk of stroke in women. JAMA. 1997; 277(19):1539-45. [PubMed: 9153368]

40. Wassertheil-Smoller S, Fann C, Allman RM, Black HR, Camel GH, Davis B, et al. Relation of low body mass to death and stroke in the systolic hypertension in the elderly program. The SHEP Cooperative Research Group. Arch Intern Med. 2000; 160(4):494-500. [PubMed: 10695689]

41. Romero-Corral A, Montori VM, Somers VK, Korinek J, Thomas RJ, Allison TG, et al. Association of bodyweight with total mortality and with cardiovascular events in coronary artery disease: a systematic review of cohort studies. Lancet. 2006; 368(9536):666-78. [PubMed: 16920472]

42. Ridker PM. Rosuvastatin in the primary prevention of cardiovascular disease among patients with low levels of low-density lipoprotein cholesterol and elevated high-sensitivity C-reac-tive protein: rationale and design of the JUPITER trial. Circulation. 2003; 108(19):2292-7. [PubMed: 14609996]

43. Kaplan RC, McGinn AP, Baird AE, Hendrix SL, Kooperberg C, Lynch J, et al. Inflammation and hemostasis biomarkers for predicting stroke in postmenopausal women: the Women's Health Initiative Observational Study. J Stroke Cerebrovasc Dis. 2008; 17(6):344-55. [PubMed: 18984425]

44. Ballantyne CM, Hoogeveen RC, Bang H, Coresh J, Folsom AR, Chambless LE, et al. Lipoproteinassociated phospholipase A2, high-sensitivity C-reactive protein, and risk for incident ischemic 
stroke in middle-aged men and women in the Atherosclerosis Risk in Communities (ARIC) study. Arch Intern Med. 2005; 165(21):2479-84. [PubMed: 16314544]

45. Wassertheil-Smoller S, Kooperberg C, McGinn AP, Kaplan RC, Hsia J, Hendrix SL, et al. Lipoprotein-associated phospholipase A2, hormone use, and the risk of ischemic stroke in postmenopausal women. Hypertension. 2008; 51(4):1115-22. [PubMed: 18259035]

46. Ikram MA, Seshadri S, Bis JC, Fornage M, DeStefano AL, Aulchenko YS, et al. Genomewide association studies of stroke. N Engl J Med. 2009; 360(17):1718-28. [PubMed: 19369658]

47. D'Agostino RB, Wolf PA, Belanger AJ, Kannel WB. Stroke risk profile: adjustment for antihypertensive medication. The Framingham Study. Stroke. 1994; 25(1):40-3. [PubMed: 8266381] 


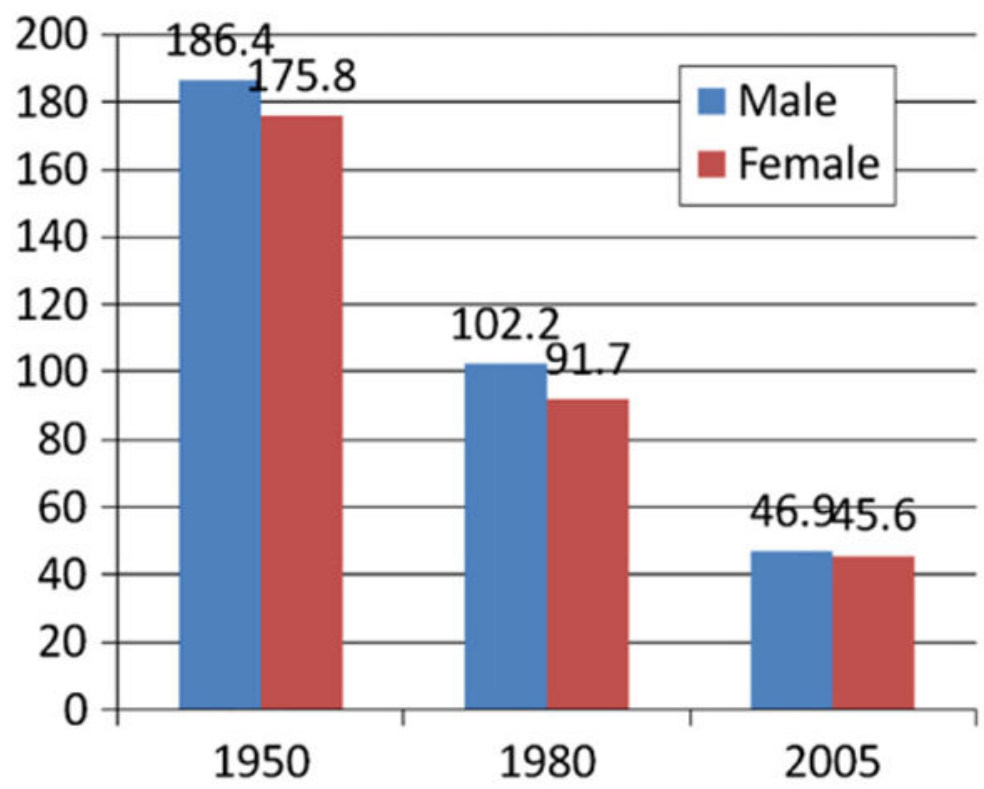

Figure 1.

Age-adjusted stroke death rates by year and sex, per 100,000 at risk. 


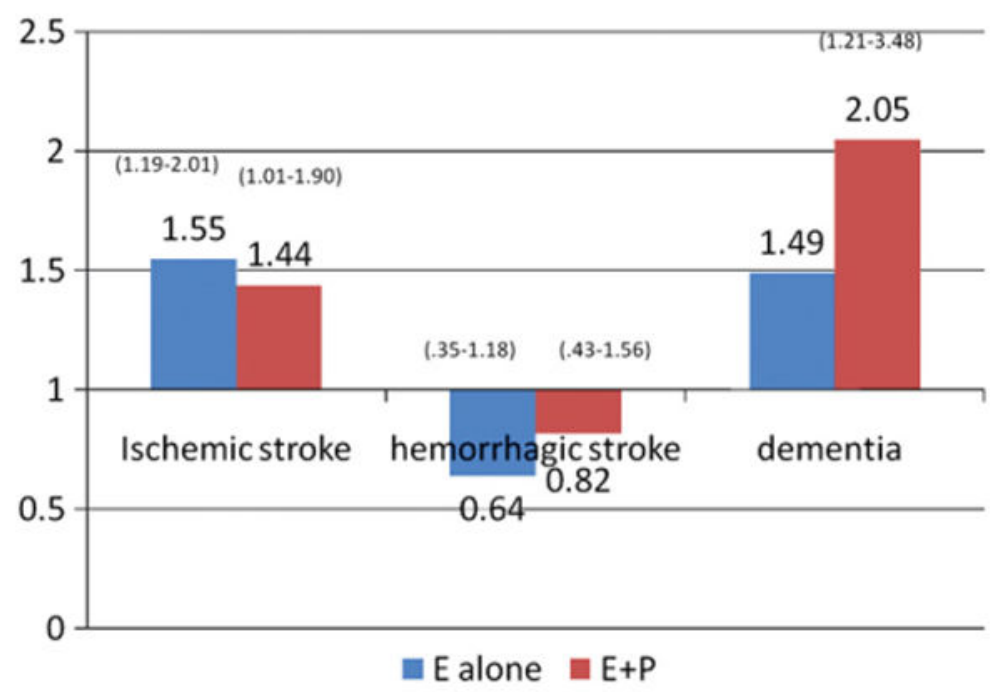

Figure 2.

Hazard ratios for stroke and dementia for hormone therapy versus placebo. 
$\%$ Risk of Ischemic Stroke in 10 Years for

Women Age 60, Framingham Stroke Risk

Score

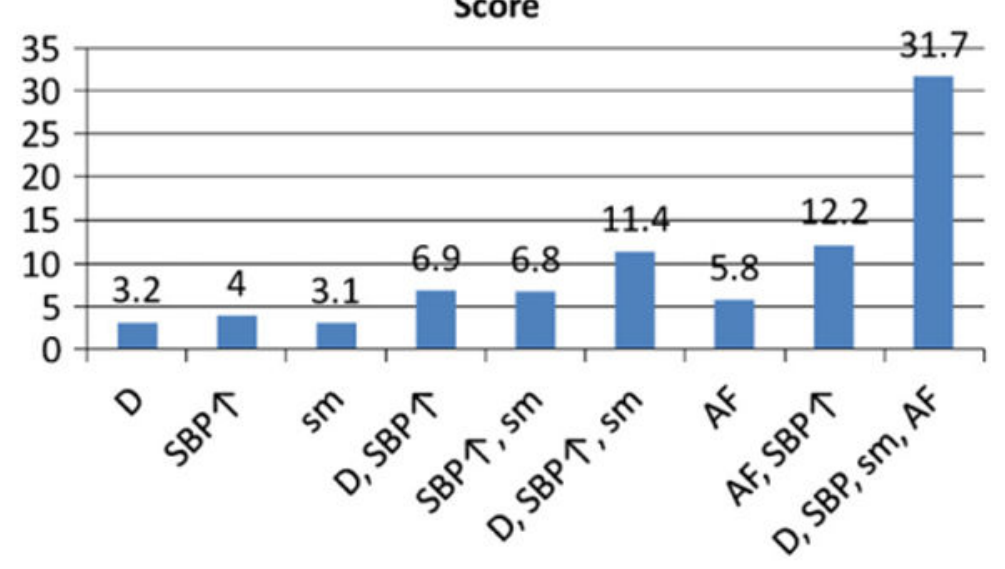

Figure 3.

Percent risk of ischemic stroke in 10 years for women age 60 as estimated by the Framingham stroke risk score for women. 